\title{
Biomass as a traditional and local source of energy in Czech Republic
}

\author{
Ščerba Eduard, Škorpil Jan \\ Faculty of electrical engieniring, Department of electrical power engieniring and ecology, \\ University of west Bohemia Pilsen, Czech Republic
}

\begin{abstract}
History of biomass energy usage in Czech Republic especially focused on phytomass and biogas.

Biomass it the oldest used fuel of the mankind (approximately 40 000years) and still today it is important worldwide source of the energy. Its proportion on the world energetic balance according to up to date source is around $16 \%$. The highest proportion of the biomass usage shows for example: Africa 50\%, Indonesia 40\%, Asia 33\%, South America 28\% and China $21 \%$.

Czech Republic has got a very long tradition in the usage of different forms of biomass for gaining energy from renewable sources (OZE). In the period of 20tees till 50tees of the last century (it means from the beginning of the first world war till the end of second world war was biomass used except from gaining of energy for heating, cooking and heating of the water also for production of the spirit, wooden coal, wood gas for drive of different machines, including cars.

The usage of biomass in Czech Republic for energetic purposes has got a dominant place comparing to other sources and possibilities of usage renewable resource of the energy as energy of wind, water, sun and so on. These days biomass participates by $65 \%$ on the total usage of the renewable resources of the energy.

State energetic policy of the Czech Republic regards biomass as an important source of energy and it assumes that it will participate on the total balance of usage of renewable resources by $80 \%$ in 2020 and by $85 \%$ in 2030 .

Renewable resources and biomass especially are basis of energetic sources for the future. Except of energetic contribution the biomass significantly contributes to the stabilization and gradual decrease of the changes on the climate by the human activity.
\end{abstract}

\section{INTRODUCTION}

\section{Basic forms and biomass sources, biomass as an energetic source}

Under the conditions of Czech Republic it is possible to state following sources of biomass according to the importance - residual wood biomass gained from mining, from wood production and from waste of wood productions. This potential is quite high and it represents approximately 2 millions of tons of dry mass per year. The price of this biomass rapidly increased because of the increased requirement from the side of big energetic sources (power stations, some heating plants). 
Energetic usage of the biomass has been recently allowed by progressive technologies of burning and also by logistic systems for gaining deliveries of this biomass and storage of this biomass.

Purposely raised biomass for the energetic usage, especially from the plants like wood species (growing of rapidly raised woods species, plantation of poplar trees and willows and agricultural land), and no wood energetic species (herbs, grass, corn). For energetically rapidly raised species and considered those that in natural conditions gain crop 10 $\mathrm{m}^{3} /$ hectare/year, which represents 4,5 t (dry mass)/hectare/ year (forest criteria, standard according to IUFRO). As an average crop under the conditions of Czech republic we consider crop from 8-10 $t$ (dry matter)/hectare/year on average for the whole existence of the plantation.

A very important portion of usage of biomass plays rape - especially and a main raw material for the production of bio petrol. Silvicultural area of this specie and increasing according to its importance.

Another important source of the biomass energy is usages of biogas gained from cleaning of sewage water, but also in bio gas stations where are processed rests and waste from agriculture and food industry. According to the decrease of agricultural food production especially decrease of keeping the cattle, but also decrease raising of food important species this decrease if substituted by other suitable plants..

Significant source of biomass energy is land fill gas gained from land fills of communal waste that are provided by establishment for getting this gas and by establishment for its burning in combination to production of the heating or electrical energy. Gained energy is used straight for usage of these properties and surplus can be given to distribution net.

For energetic usage is also more and more used production of ethanol from corn, that is added as a gas in some rate to the petrol. Amount and quality of the ethanol that is to be added to the petrol is controlled and regulated by law.

\section{BODY OF THE PAPER}

\section{Total amount of biomass production in Czech Republic, Potential of biomass in Czech Republic.}

The potential of biomass in Czech Republic can be divided into some parts - from theoretical, technical to economical accessible one. This range of potentials includes character of the surrounding, technologies, legislative and other limitation including economical tools expressing competing abilities for possibilities of biomass usage in that specific setting.

Czech Republic belongs according to studies and analyses of biomass production potential (by British firm CSMa 1997) to the countries with relatively high and accessible potential of biomass that moves around 11-16 millions of tons of dry mass per year, which corresponds to energetic potential c. (210-290 PJ/year).

If this accessible potential could be developed and used including purposely raised biomass in that way that biomass could participate on energetic balance in CR in 2030 by c. $12 \%$ (source MPO 2004).

From the accessible potential of the biomass is according to different authors 2,2-6,5 millions of tons/year which represents energetic potential so called residual and waste biomass. Currently is according to estimation (Ministry of the environment) used about 2 millions of tons, which is approximately $1 / 3$ of potential of residual biomass and 1/5 of total accessible potential of biomass. 
The potential of purposely raised biomass from energetically wood (RRD) but also not wood species is estimated to 4-9 millions of tons/year which represents energetic potential c. (75$165 \mathrm{PJ} /$ year). This potential could be used in the horizon of 20-30 years.

\subsection{The usage of biomass for the heating production and electrical energy production.}

Biomass is presently used in Czech Republic the most often for the production and distribution of the heating in local and central systems of providing the heating. Here are concerned especially small heating plants for villages and cities that often also handle sources of biomass (forest, fields, meadows and so on).

The ownership of the sources and also of the establishment is very important in terms of the economy of the production of the establishment and in terms of the price of the heating sold to the citizens. It is also very traditions to use biomass for production of the heating for family houses and small factories.

Within the period starting from the year 2004 in Czech Republic started to increase the proportion of biomass usage in big heating plants and power stations. This huge increase was allowed by legislation that makes more profitable electric energy that is produced from biomass. This consequently increased the requirement for biomass which also increased the prices of biomass.

The big energetic companies may afford increase of the price of biomass and may afford it, on the other hand by smaller companies the increase of the biomass prices is reflected into the increase of the price of energy for citizens. According to the information that is accessible in years $2003-2004$ the price of biomass increased by c. 1/3. The other fact is that potential of biomass that is accessible is taken into parts by some big sources that add this biomass in some rate (10\%-20\%) to the coal. According to the proportion of biomass and total amount of energy that was produced these companies get higher selling price for the energy - so price profit that is guarantied by state. The consequence of this state is that biomass lacks or its price is not accessible on the places where its usage for individual or local production of the heating in terms of economical and environmental would be much more important. High price of the biomass and its inaccessibility leads people to use for heating cheaper coal. Burning of coal in local sources causes much higher environmental load in comparison to big energetic sources that are capable to decrease this load. These are especially final technologies for catching firm elements and gas pollutions as sulphur oxide, nitrogen and so on.

Production of electric energy from biomass is proceeded especially in energetic establishments of power stations and heating plants by traditional way of direct burning or joint-burning of biomass. In lower extent while energetic usage of biogas and waste gas in classical combined heat and power units, or by help of items with Stirling engine.

Pellets and briquettes from biomass mean very progressive development. Using them is less time demanding and also service is less demanding too, automatization and optimalization while using those increases. These are concentrated and size suitable kinds of fuels that are easy to be stored and automatically dosed to burning establishments specially modified for these pellets and briquettes. Boilers and also especially modified for these kinds of fuel. In Czech Republic increased offer of pellet an briquettes producers and also for establishments using them. 


\section{ACKNOWLEDGEMENTS}

\section{Economical and energetic aspects of bio fuel usage}

Concerning higher requirement of biomass also the prices of biomass increases. As the price increases they can not compete to classical fossil sources especially to brown coal. Up to date trends will still represent this price increase of biomass as the sources of brown coal and exhaustible, but also because of the state policy, that supports big energetic giants that dictate prices and accessibility of the biomass on the markets. This situation may change by the change in the legislation, but also by higher support of the production and by increase of competitive strength of accessible potential of biomass raised on purpose for energetic purposes...

\subsection{Environmental contribution of biomass usage}

In case of biomass burning there is relieved into the atmosphere only that amount of the carbon dioxide that was from the atmosphere taken for the production of the biomass by photosynthesis. Another contribution of gaining biomass for energetic purposes if usage of field for non food production and it that way creation of job opportunities, last but not least importance is in the care of the countryside and increase energetic independence of the cities and regions.

While raising and energetic usage of biomass there do not create any further significant environmental burdens in comparison to for example: fossil sources.

This paper was written under solving science project GAČR 102/06/0132

\section{Authors address:}

Mgr. Eduard Ščerba, Ph.D.

Faculty of electrical engieniring, Department of electrical power engieniring and ecology, University of west Bohemia Pilsen, Czech Republic

Establishment: Univerzitní 8, 30614 Plzeň, Czech Republic

Tel:+42037763311

E-mail: scerba@kee.zcu.cz

\section{REFERENCES:}

(1) H. Scholes , M. Maning, T. Markvart Czech Republic Renewable Energy StudyResource Assesment report 1997

(2) GRENN PAPER 2001, Towards a European Strategy for the security of energy supply. Europan Commision

(3) J.Weger, K.Havlíčková a kol.Biomasa obnovitelný zdroj energie v krajině, VÚKOZ Průhonice 2003

(4) K.Havlíčková, J.Knápek, J.Vašíček, J.Weger Biomas as reneweble source of energy, Economic and energy aspect VÚKOZ Průhonice 2005 